\title{
The Facility Planning and Electric Power Quality of the Saroma Lake Green Microgrid by the Interconnection of Tidal Power Generation, PV and SOFC*
}

\author{
Shin'ya OBARA**, Osamu KAWAE***, Yuta MORIZANE** \\ and Masahito KAWAI**** \\ ${ }^{* \star}$ Kitami Institute of Technology, Power Engineering Lab., Dep. of Electrical and Electronic Engineering \\ Koen-cho 165, Kitami, Hokkaido, Japan \\ E-mail: obara@mail.kitami-it.ac.jp \\ ${ }^{* * * T e c h n o l o g y ~ I n n o v a t i o n ~ C e n t e r, ~ A s a h i k a w a ~ N a t i o n a l ~ C o l l e g e ~ o f ~ T e c h n o l o g y ~}$ \\ Shyunkoudai 2-2-1-6, Asahikawa, Hokkaido, Japan \\ ****Support Center for Engineering Education, Hakodate National College of Technology \\ Tokura-cho 14-1, Hakodate, 042-8501, Japan
}

\begin{abstract}
Tidal power generation is viewed as a leading green energy approach. It is expected that the use of tidal power generation will become a primary method for local-supply-and-local-consumption energy, similar to photovoltaics and wind power. Because the current produced by tides changes with a definite periodicity, it is straightforward to forecast the production of electricity by tidal power generation. However, to cover the supply-and-demand differences in electric power, an accumulation-of-electricity system or a controllable electric power source is required. Hence, in this paper, the cost and electric power quality of an interconnection system constructed with a solid oxide type fuel cell (SOFC), photovoltaics $(\mathrm{PV})$, and tidal power generators are investigated. By accessing the high-speed tidal current in the lake inlets of the Saroma Lake in Hokkaido, the demand of electric power and heat in a surrounding area are provided by the proposed system. As a result of the estimations of numerical analyses, the facility planning, costs, and electric power quality of the proposed system are identified, and the amount of time required to recover the cost versus the present energy cost is expected to be approximately ten years.
\end{abstract}

Key words: SOFC, Tidal Power Generation, Microgrid, Lake Saroma, Numerical Simulation, Okhotsk

\section{Introduction}

Tidal power generation is examined as a type of green energy for possible exploitation in Japan ${ }^{(1,2)}$. The examples of tidal power generation implemented in Scotland and South Korea have recently become well known $^{(3-6)}$. In addition to the use of photovoltaics and wind generation in Scotland, it is thought that tidal power generation will mature into a leading source of green energy. Because tidal power is generated by tides, the forecasting of power changes is straightforward. The velocity and direction of a tide change with the cycling of high and ebb tides and, hence, vary within a given period; yet in this case, to cover the supply-and-demand differences in power, the installation of 
accumulation-of-electricity equipment, the introduction of a power supply of variable output power, an interconnection with other power supply networks including commercial power, etc., are all required. However, even the absorption of generated tidal power fluctuations accomplished by the interconnection of tidal power systems with commercial power systems is insufficient to ameliorate the total amount of variability introduced, with the consequence that tidal power generation will continue to be restricted in practice, much like other green energy systems. Accordingly, in this paper, an independent microgrid is established to separate a tidal power system from other electrical power systems; the purpose of our investigation is (1) to clarify the characteristics of the electrical power system used with the tidal power generator and (2) to develop a local power supply with local energy consumption. Because independent microgrids tend to lack surplus power production capacity, it is important to optimize the operation of the system with respect to the quality of power and electric facilities as well as the cooperative control of each equipment item. To the best of our knowledge, this report of a microgrid established from combined power sources, including a tidal power generator with a heat supply, is the first investigation of its kind.

As an example of independent power established by the application of a tidal power generator, this work examines the Saroma Lake green microgrid (SLMG), which was installed in the Sea of Okhotsk at the coastal area of Hokkaido. Because the area surrounding Saroma Lake is cold and snowy, the heat demand in winter is very high. Moreover, because there is no large-scale power plant within the region, the power that serves the area surrounding Saroma Lake is supplied by long-distance power transmission lines, which originate from a variety of locations in Hokkaido. Therefore, this area has conditions suitable for the introduction of a local power supply, combined with a local consumption of the produced energy. The area surrounding Saroma Lake contains an expanse of land, ocean, lakes, rivers, etc., as well as a quickly changing tide, which is evident in the two lake inlets that connect the ocean and the lake. Accordingly, the facility and operational costs of the SLMG and the quality of the electric power (frequency, voltage, waveform) produced through the use of a tidal power generator, photovoltaics (PV), fuel cells (SOFCs: solid oxide type fuel cells), a heat pump, and a heat storage tank are numerically analyzed in this paper. Based on the results described, the possibility of introducing an independent microgrid for the supply of electric power and heat to the area surrounding Saroma Lake is considered by using three types of supply capability, including tidal power generators, PV, and SOFCs.

\section{Proposed System}

\subsection{Introduction to the Area of Saroma Lake}

The Saroma Lake in Hokkaido is the third largest lake in Japan. The area surrounding Saroma Lake has rich fishing resources, such as scallops, shrimp, and oysters, and is an important area for archaeological inquiries, specifically those pertaining to the Okhotsk and Ainu cultures. As shown in Fig. 1, the first lake inlet is approximately $300 \mathrm{~m}$ in width, while the second lake inlet is approximately $75 \mathrm{~m}$ in width. Within these lake inlets is a stable tide derived from the ocean tidal cycle. Although the tide is also dependent on the depth of the water, this tide changes at approximately $2 \mathrm{~m} / \mathrm{s}^{(7,8)}$. Therefore, plans have been made to install tidal power generators in the ocean near the lake inlets to establish an independent microgrid without the need for external power sources (except for an emergency source) to supply electric power and heat to the surrounding town, harbor facilities, etc. The tidal current speed near the inlets to Saroma Lake follow the cycle of the tide; therefore, to accommodate fluctuations in the generation of power by tidal changes, an interconnection system of photovoltaics and solid oxide type fuel cells (SOFCs) was constructed. The independent microgrid, in accordance with the interconnection of each supply capability 


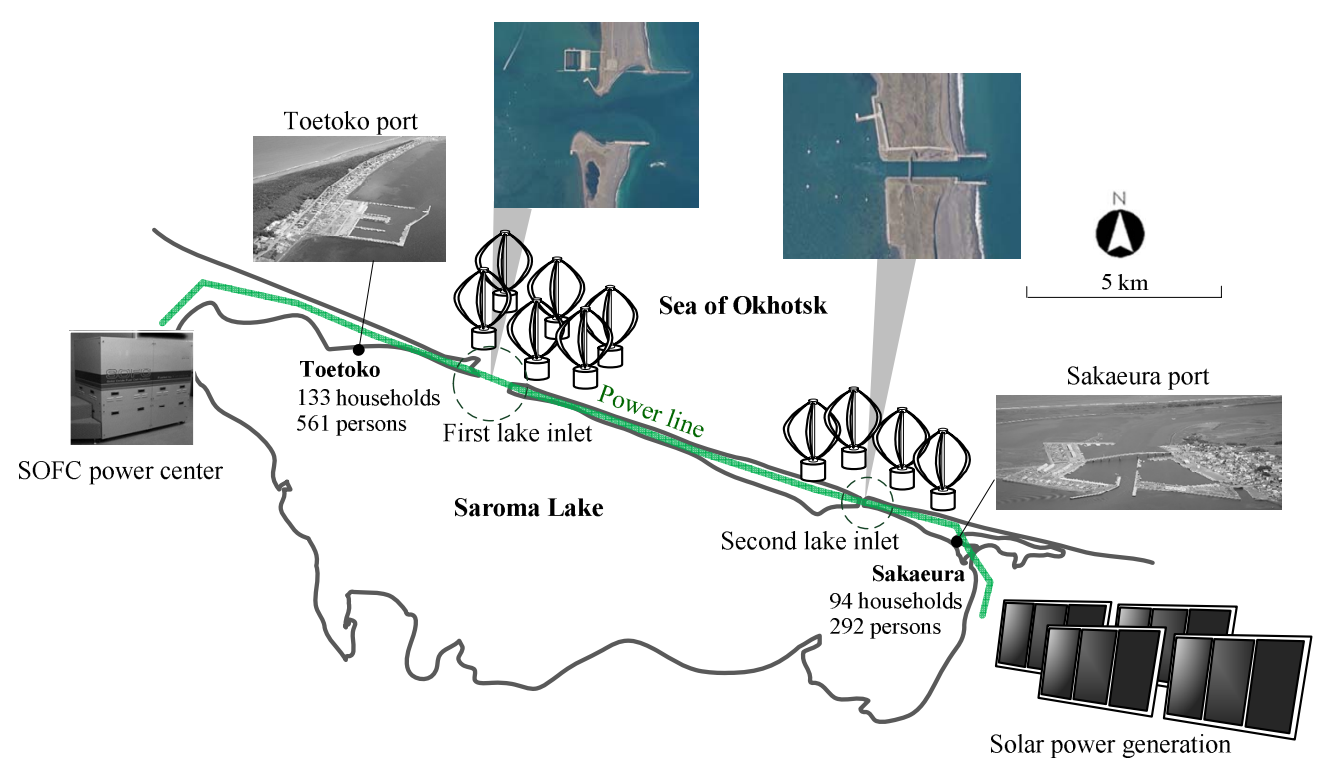

Fig. 1 The power system of the Saroma Lake green microgrid

described above, is described as the Lake Saroma green microgrid (SLMG), which is further detailed below. The characteristics of the local supply and the local consumption system can be clarified by considering the independent microgrid. The electric power is supplied from the SLMG to two towns (Toetoko and Sakaeura) as well as to two fishing ports by an independent power transmission line. Moreover, the exhaust heat of the SOFCs and the heat from the heat pump are supplied to the same area by a hot water network, through the use of a heat storage tank. The number of households is 133 and the population of Toetoko is 561, while there are 94 households and 292 persons in Sakaeura.

\subsection{System Configurations}

\subsubsection{Supply Capability}

Figure 2 shows a block diagram of the SLMG created by MATLAB/Simulink 2012a. The SLMG is an interconnected system including (a) a tidal power generator installed near the two lake inlets, which connect the open sea to Saroma Lake (tidal power generator systems a and b), (b) SOFCs powered by natural gas, and (c) a PV power generator; overall, this system provides an independent power network for a fishing village that is subject only to local energy sources and requires no external power. It is necessary to adjust parameters of each block and to tune up specifications of the proposed system so that electric-power quality (voltage, frequency, and waveform) of power grid may not be spoiled. A power transmission line of analysis model is constructed from Toetoko to Sakaeura, and the electric power of each supply capability is supplied to the transmission network through an inverter and a harmonics filter. The power supply is a three-phase alternating current of 400 $\mathrm{V}$ (effective value) and $50 \mathrm{~Hz}$, and the full length of the power transmission line is approximately $25 \mathrm{~km}$. The tide current is changed into electric energy by installing two or more small-scale Darius-type water wheels of $5 \mathrm{~kW}$ in the seabed near both the first and second lake inlets. Moreover, the large-scale solar power plant in this area and the SLMG are interconnected, and the supply-and-demand difference in electric power is adjusted using the power produced by the SOFCs. Because the heat-to-power ratio is very high and a significant quantity of heat is demanded during the winter in the study area, the energy of the supply capabilities can be stored as heat by introducing thermal storage equipment. However, the accumulation-of-electricity equipment does not take this installation into consideration in clarifying the limitations of facility costs or the power quality.

\subsubsection{Synchronization of the Supply Frequencies}

The frequency of the AC power supplied to the load from each of the supply capabilities must be synchronized. In all of the supply capabilities presented, only the 


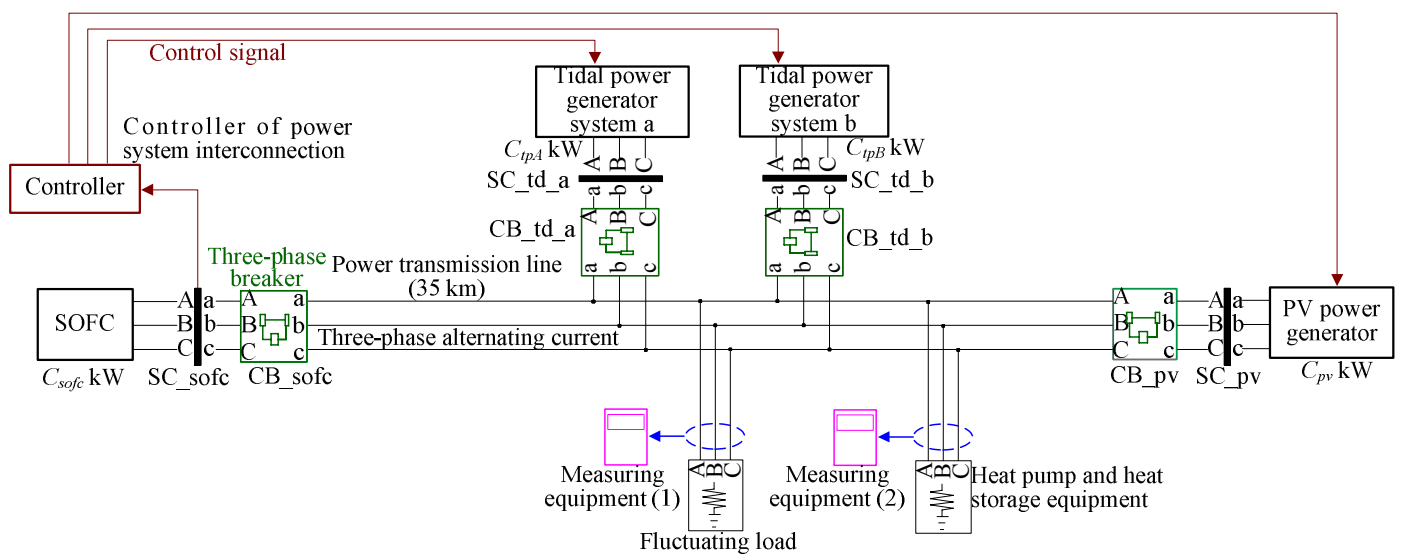

Fig. 2 The electrical power system of the SLMG, as defined by MATMAB/Simulink

frequency of the SOFCs can be readily controlled. Because the PV and the tidal power generators have a time period of generation that depends on environmental conditions and is not innate, the SOFCs must play the base power supply role. Therefore, the SOFCs must always be operating, so the frequency of electric power generated by the SOFCs is set to a standard frequency in this paper. Similarly, the frequency of each power supply capability is adjusted by the use of inverters. The system controller measures the frequency of the bus line of the SOFCs, and the controller transmits the control signals necessary to synchronize the SOFC frequency with that of each inverter.

\subsubsection{Production of Electricity and Fluctuation of the Power Load}

The power load varies over a period of less than several seconds; the load also experiences variations on daily and yearly (seasonal) timescales. Because the heat loads differ greatly from the summer season to the winter season, the seasonal change in electric power load is significant. The heat-to-power ratios for both the electricity demand and the heat demand for a representative summer day (August) and a representative winter day (February) are 1.0 and 11, respectively. Moreover, the heat-to-power ratio is as high as 26 at 6:00 in the morning during February. Because the exhaust heat of the SOFCs and the heat produced by the electric heat pump correspond to the heat load of the SLMG, the difference between the electric power load in summer and winter for the proposed system becomes extremely high. Consequently, the load pattern of the power and the heat demand in February, which has a large heat-to-power ratio, leads to the annual maximum of electricity demand; hence, the equipment plan and operation method required to meet this demand based on the proposed system are investigated here.

\subsection{System Control}

The difference in the supply capability of combined PV and tidal power generation versus the electric power load, in light of the electric power consumption of the electricity demand and the heat supplied by the pump, is supplied within the system with the power control of the SOFCs. However, it is necessary to supply all surplus power to the operation of the SOFCs at a maximum heat pump load in winter, when the heat demand is significant. The $\mathrm{a}$ and $\mathrm{b}$ tidal power generator systems identified in Fig. 2 are installed in the seabed near the first and second lake inlets, respectively, and these generators possess equivalent power generation capacities. The power output of the tidal power generator changes in accordance with the speed of the tidal current. However, the outputting point of the PV system is controlled in such a way that its maximum is determined by the MPPT (Maximum Power Point Tracking) control, while the outputting point of the SOFCs is controlled by the rated operational control. Accordingly, the outputting point of the power is controlled by each supply capability except the tidal power generator; further, as described in Section 2.2.2, the frequency of each supply capability is controlled based on the frequency of the AC power generated by the SOFCs. 


\section{Supply Capabilities}

\subsection{Photovoltaics (PV)}

Figure 3 (a) shows the current-voltage characteristics of the PV for a maximum output of $1000 \mathrm{~kW}$, with a module area measuring approximately $5560 \mathrm{~m}^{2}$. The maximum power-generation efficiency of the solar cell is $18 \%$, and assumes the present average products. As shown in the SLMG analysis described in the next section, the current-voltage characteristics of the hypothetical PV introduction are partially dependent on the results in Fig. 3 (a), which correspond to the area of cell module that must be introduced. The power generated by the PV system is always dependent on the current and voltage of the maximum output point, as dictated by the MPPT control.

Figure 3 (b) presents a block diagram of the PV, developed with MATLAB/Simulink, and Fig. 3 (c) shows a block diagram of the MPPT control of the PV. The current-voltage characteristics of the set up used for Fig. 3 (a) correspond to the modular area, and this value is initially input into the red block in Fig. 3 (c). Because the PV power changes correspond to the amount of insolation, the fluctuation pattern of insolation required for the simulation is input into the green block in Fig. 3 (c) beforehand.

As shown in Fig. 3 (b), a snubber circuit, consisting of a resistor and a capacitor, is introduced after the PV array system. Any potential damage to the DC-DC converter or the inverter that could arise as the result of rapid changes in the amount of insolation are otherwise prevented by the use of a snubber circuit. The DC-DC converter increases the

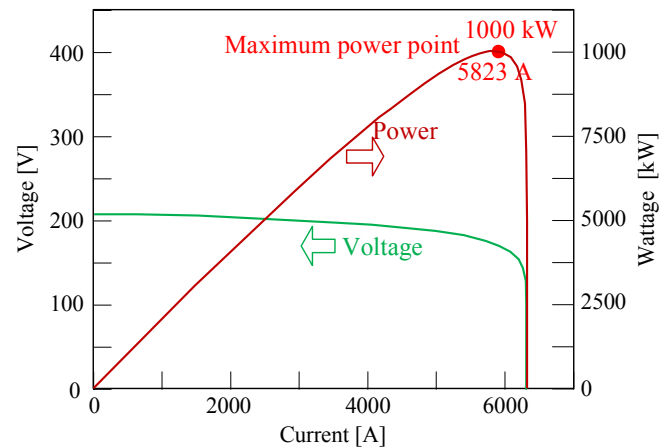

(a) The output characteristics of the PV system

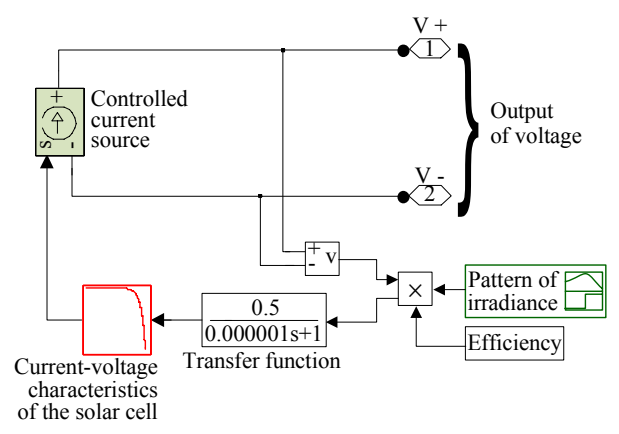

(c) The PV system with the output PV characteristics

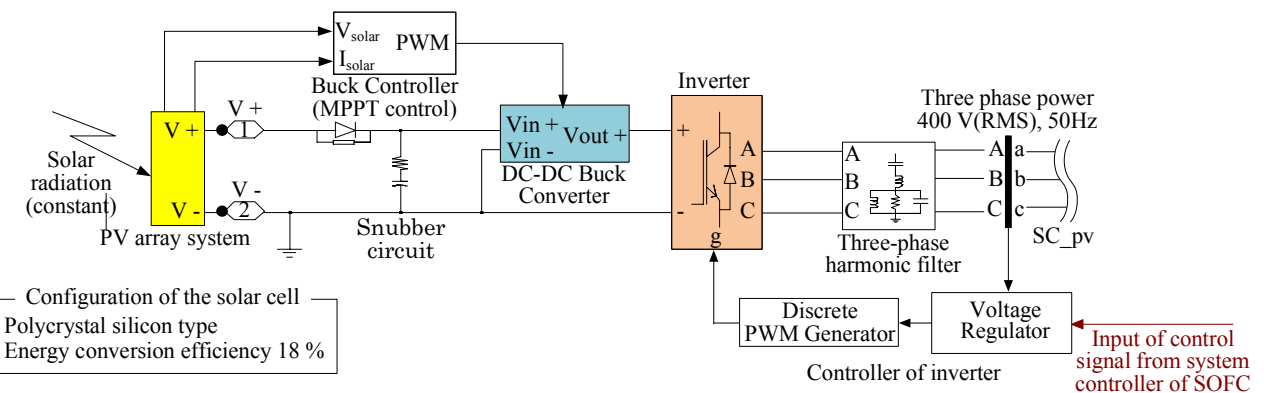

(b) A block diagram of the PV power generator

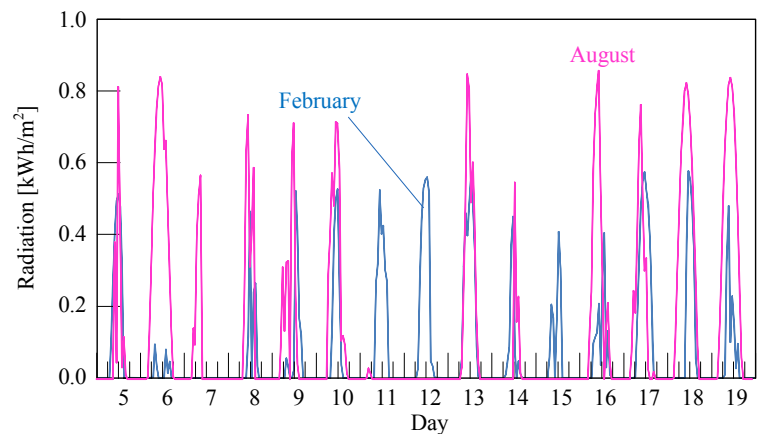

(d) The global solar radiation

Fig. 3 The PV system
Table 1 The specifications of the SOFCs

\begin{tabular}{|l|}
\hline \multicolumn{1}{|c|}{ In the case of capacity $5 \mathbf{5 5 0} \mathbf{~ k W}$} \\
Number of cells 2700 \\
Nominal operating point $200 \mathrm{~A}, 2750 \mathrm{~V}$ \\
Maximum operating point $616 \mathrm{~A}, 2150 \mathrm{~V}$ \\
Nerst voltage of one cell $1.1865 \mathrm{~V}$ \\
Nominal stack efficiency $55 \%$ \\
Operating temperature $1275 \mathrm{~K}$ \\
Nominal Air flow rate $0.233 \mathrm{~m}^{3} / \mathrm{s}$ \\
Nominal supply pressure, Fuel $0.2 \mathrm{MPa}$, \\
Air $0.15 \mathrm{MPa}$ \\
Nominal utilization Hydrogen $67.7 \%$, \\
Oxigen $79.2 \%$ \\
\hline
\end{tabular}




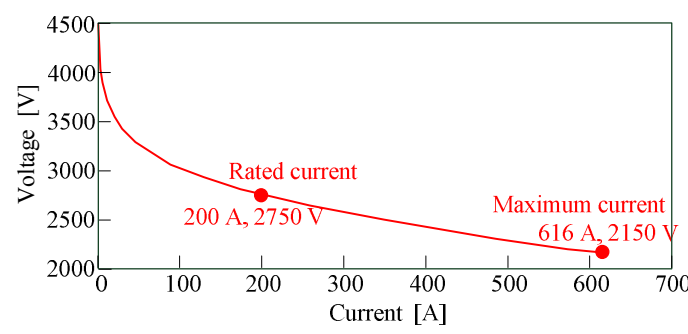

(a) The output characteristics of the SOFC and the stack voltage vs. the current

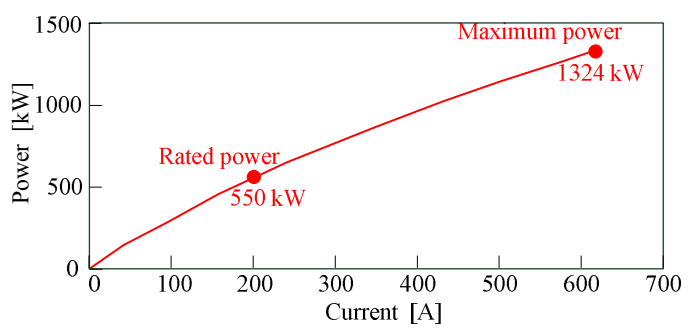

(b) The output characteristics of the SOFC and the stack power vs. the current

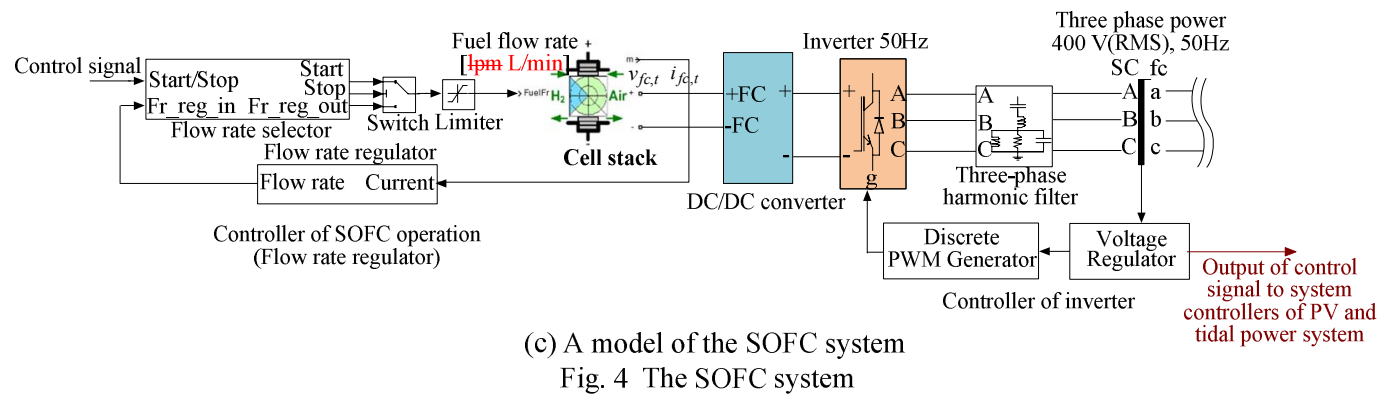

output voltage of the solar cell module to the effective value of $400 \mathrm{~V}$; additionally, the control commands are transmitted to the PV system inverter controller (shown in Fig. 2), such that the electric power output from the PV to the SLMG can be synchronized with the SOFC power frequency. After the electric power output from the PV inverter passes the harmonics filter, the electric power is then supplied to the SC_pv bus line. The power specifications of the SC_pv bus line demand that the effective voltage be $400 \mathrm{~V}$ with a $50-\mathrm{Hz}$ three-phase alternating current. The constants set for each block in Fig. 3 were determined based on knowledge of the actual equipment.

Figure 3 (d) shows the measured values of the average global solar radiation, collected between the 5th and 19th in the winter season (February) and the summer season (August) in 2010 for the Saroma Lake surrounding area ${ }^{(7)}$. During winter, the Saroma Lake surrounding area is often covered by snow, and the amount of insolation in winter is generally low compared with the other seasons.

\subsection{SOFCs}

Figures 4 (a) and (b) display the current-voltage characteristics (Fig. 4 (a)) and the current-output characteristics (Fig. 4 (b)) for a $550 \mathrm{~kW}$ rated output of the SOFCs. The output characteristics of the SOFCs shown in Figs. 4 (a) and (b) were decided by referring to the power characteristics of SOFC for residences (ENE - FARM [9]) currently produced commercially, and increasing capacity relatively. Although the introductory capacity of the SOFCs is arbitrarily given in the analysis, the current-voltage characteristics and the current-output characteristics of the SOFCs incorporate the output characteristics of Figs. 4 (a) and (b) by using relative adjustments (i.e., equivalent to the change in the number of cells). The SOFCs are operated by rated operation control; hence, the fuel cells may always be used at the rated output point.

Figure 4 (c) shows a block diagram of the SOFC. The output characteristics of the SOFC stack displayed in Figs. 4 (a) and (b) are input beforehand into the block of the cell stack, as shown in Fig. 4 (c). Moreover, Table 1 includes the specifications of the SOFCs for a $550 \mathrm{~kW}$ rated output, as given in Figs. 4 (a) and (b). If the startup control signal is input into the flow rate selector, then natural gas and air will be supplied to the SOFCs and the production of electricity will commence. From the flow rate selector, the control commands of the startup operation (Start), the stop operation (Stop), and the rated operation (Fr_reg_out) are all sent to the fuel cell. The frequency and voltage of the electric power output of the SOFCs are controlled by a DC-DC converter and an inverter in accordance 


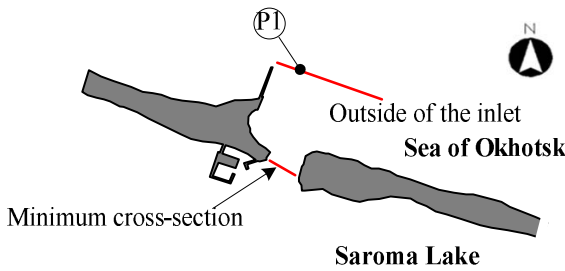

The first lake inlet

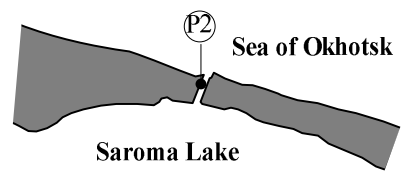

The second lake inlet

(a) The points of observation

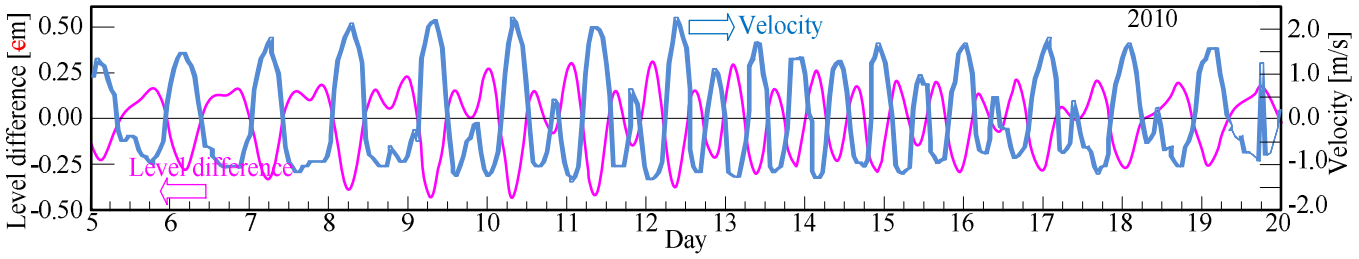

(b) The difference in the tide level between Saroma Lake and the Sea of Okhotsk and the flow velocity of the current

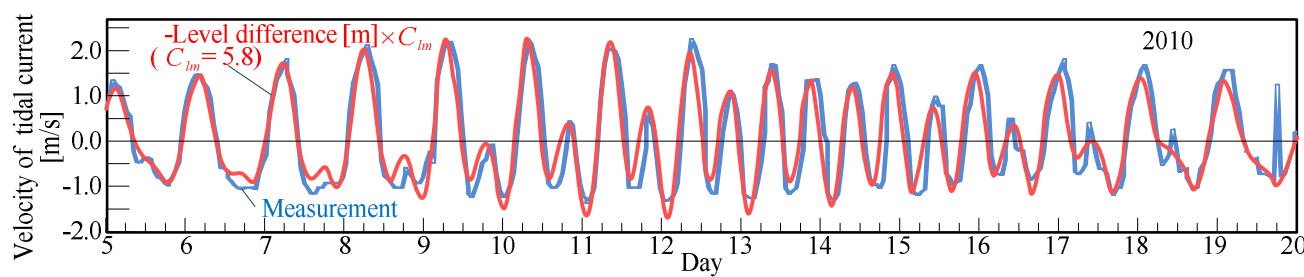

(c) The relationship between the difference in the tide level of Saroma Lake and the Sea of Okhotsk and the flow velocity of the current

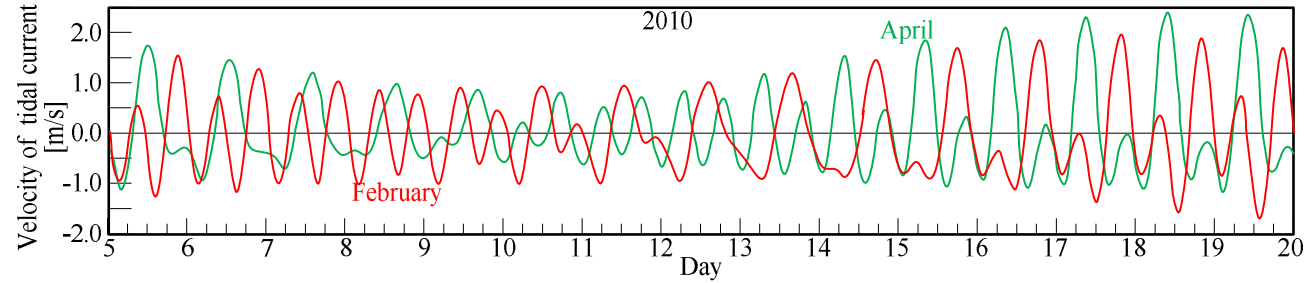

(d) Forecast of the flow velocity of the current for February and April

Fig. 5 The tide level and flow velocity of the current at the inlet of Saroma Lake

with the rated value. The power specifications of the $\mathrm{SC}_{-} \mathrm{fc}$ bus line are $50 \mathrm{~Hz}$ with a three-phase alternating current and an effective value of $400 \mathrm{~V}$.

\subsection{Tidal Power Generation System}

\subsubsection{Velocity of the tidal current}

The tidal current and geographical features of the inlets to Saroma Lake have been widely investigated in the past ${ }^{(8,10)}$. P1 is given as the first lake inlet point, and P2 is taken as the second lake inlet, as shown in Fig. 5 (a). These positions were employed in the tidal current investigation set up from August 5th to 19th, 2010. The established positions of the tidal power generators are assumed to be near P1 and P2. Figure 5 (b) shows the measurement results of the flow velocity of a north-south component as well as the tide level difference in August for P1 (where the water depth is $6 \mathrm{~m}$ at the first lake inlet) ${ }^{(8)}$. The tide level difference described above is due to the difference in height between Saroma Lake and the Sea of Okhotsk, in which flow from Saroma Lake to the Sea of Okhotsk produces the low tide (north-facing flow), while flow from the Sea of Okhotsk to Saroma Lake produces a flood tide (south-facing flow). The peak flow velocities occur between two and five times per day following the low tide and flood tide. Because the direction of the tidal flow reverses between the flood tide and the ebbing tide, the rotative or operational direction of the tidal power generator must also be reversible. Furthermore, the tide level difference and the tidal current speed are strongly related, and this relationship can be introduced by the approximate expression given in Eq. (1): 
$v_{w, t}=C_{l m} \cdot\left(-L_{t}\right) \quad$ where $C_{l m}$ is a constant.

$C_{l m}$ in Eq. (1) can be calculated from correlations of the measurement results for the tide level difference and the tidal current speed. If the value of the tide level difference shown in Fig. 5 (b) is reversed based on Eq. (1) and if the proportionality coefficient $C_{l m}$ is given, the tidal current speed has a strong, opposite correlation to the tide level difference, as shown in Fig. 5 (c). Because the tide level difference at any given time is reported in detail by the Japan Coast Guard ${ }^{(11)}$, the speed of the tidal current can be readily predicted as a function of time. Figure 5 (d) shows the results of the tidal current speed predicted by defining $C_{l m}$ with the tide level difference of P1 from February 5th to the 19th (winter) and from April 5th to the 19th (in between seasons).

3.3.2 Kinetic energy of the tidal current and the tidal power generator

The tidal current speed at a sampling time $t$ is $v_{w, t}$, and $m_{w, t}$ is the mass that flows into area $S$ in 1 second, such that the kinetic energy $P_{w, t}$ of the tidal current can be obtained by Eq. (2):

$$
P_{w, t}=\frac{1}{2} \cdot m_{w, t} \cdot v_{w, t}{ }^{2} \quad \text { where } m_{w, t}=\rho_{w} \cdot S \cdot v_{w, t} .
$$

The introduction of a Darius-form water wheel with a height of $1.9 \mathrm{~m}$ and a rotation diameter of $1 \mathrm{~m}$ is assumed for the tidal power generator (Fig. 6). A Darius-form water wheel has an insignificant influence on the change in flow of a tidal current, and the wheel can adjust to changes in the tidal current that occur as the result of low and flood tides. The rated output and water wheel efficiency of the Darius-form

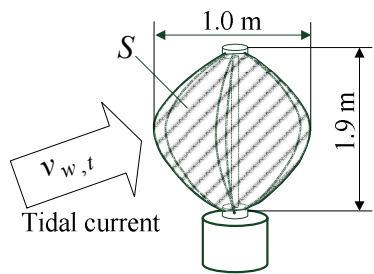

Fig. 6 Darius-form water wheel water wheel are $5 \mathrm{~kW}$ and $35 \%$, respectively. By multiplying the value of $P_{w, t}$ from Eq. (1) and the water wheel efficiency, the output of the tidal power generator can be obtained.

Figure 7 shows a block diagram of the tidal power generator. The tidal power generator introduces identical capacity equipment at both the first and second lake inlets; in particular, Fig. 7 shows the system installed in the first lake inlet. The effective voltage of the corresponding power specification of the SC_tp_a bus line given in Fig. 7 is a three-phase alternating current with $400 \mathrm{~V}$ and $50 \mathrm{~Hz}$. Although the electric power output of the tidal power generator depends on the magnitude of the tidal current speed, the frequency of the SC_tp_a bus line is controlled by the control signal transmitted from the SOFC system controller, which synchronizes the tidal power frequency with that of the electric power generated by the SOFCs. The tidal current speed, as shown in Figs. 5 (c) and (d), is introduced into Eq. (2); by multiplying with the water wheel efficiency, the energy of the tidal current at a sampling time $t$ can be calculated. By giving the energy of the tidal current as $P_{w, t}$ in Fig. 7, the pattern of the electric power output of the tidal power generator is obtained.

\section{Investigation of the Installed Capacity and the Method of Operation}

\subsection{Energy Balance Equations}

Equation (3) gives a formula for the electric power balance at a sampling time $t$ for the given power network and heat distribution network of the SLMG. The left side of Eq.

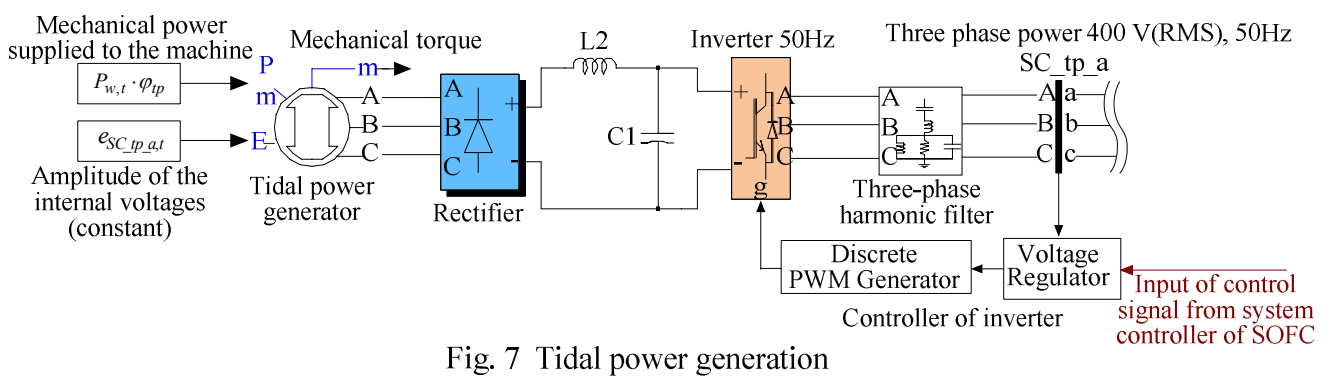


(3) gives the electric power output items, and the right side includes the electric power consumption items. The electric power is supplied to the power network from $N_{\text {tidal }}$ sets of tidal power generators, the PV and the SOFCs in the SLMG. However, the electric power is consumed by the electricity demand $\Delta p_{e, n e e d s, t}$, the power consumption $\Delta p_{e, h p, t}$ of the heat pump, and the electric power loss $\Delta p_{e, \text { loss }, t}$ of the right side of Eq. (3). As shown in Eq. (4), the electricity demand $\Delta p_{e, n e e d s, t}$ is the sum total of the electricity demand $\Delta \bar{p}_{e, T, t}$ and $\Delta \bar{p}_{e, S, t}$ of the time average of $N_{T}$ houses in Toetoko and $N_{S}$ houses in Sakaeura as well as the electricity demand $\Delta p_{e, \text { facilities }, t}$ of the harbor facilities. Moreover, the losses due to inverters and converters and the power transmission losses are included in the electric power loss $\Delta p_{e, l o s s, t}$. When the electric power is reduced due to lower tidal power generation and PV output versus power consumption (the right side of Eq. (3)), the fuel cell provides for the discrepancy. However, when the electric power generated by the tidal power generation and the PV output exceed the power consumption, the excess electric power is supplied to the heat pump. Because the excess heat is stored within a heat storage tank, the heat can be supplied to the demand side at later times.

Equation (5) is the heat balance equation for the SLMG. The left side of Eq. (5) is the output of the heat pump ( $\left.p_{h, h p, t}\right)$, the exhaust heat of the SOFCs $\left(p_{h, s o f c, t}\right)$, and the heat storage output ( $\left.p_{h s t, t-1}\right)$; meanwhile, the right side includes the heat demand $\left(\Delta p_{h, \text { needs }, t}\right)$, the heat storage $\left(\Delta p_{h s t, t}\right)$, and the heat radiation loss $\left(\Delta p_{h, l o s s, t}\right)$. The amount of heat radiated by the heat storage tank and the hot water piping is included in $\Delta p_{h, l o s s, t}$. Furthermore, the power consumption $\Delta p_{e, h p, t}$ of the heat pump is obtained from Eq. (6) using the coefficient of performance $C O P_{h p}$.

$$
\begin{aligned}
& \sum_{i=1}^{N_{\text {hite }}} p_{e, t i d a l, i, t}+p_{e, p v, t}+p_{e, s o f c, t}=\Delta p_{e, \text { needs }, t}+\Delta p_{e, h p, t}+\Delta p_{e, \text { loss }, t} \\
& \Delta p_{e, \text { needs }, t}=N_{T} \cdot \Delta \bar{p}_{e, T, t}+N_{S} \cdot \Delta \bar{p}_{e, S, t}+\Delta \bar{p}_{e, h p, t}+\Delta p_{e, \text { facilities }, t} \\
& p_{h, h p, t}+p_{h, s o f c, t}+p_{h s t, t-1}=\Delta p_{h, \text { needs }, t}+\Delta p_{h s t, t}+\Delta p_{h, \text { loss }, t} \\
& \Delta p_{e, h p, t}=p_{h, h p, t} / C O P_{h p}
\end{aligned}
$$

\subsection{Characteristics of the Auxiliary Equipment and the Unit Price of the Equipment}

For the electric power loss $\Delta p_{e, \text { loss }, t}$ on the right side of Eq. (3), a value of $10 \%$ is given as the loss of the DC-DC converter and the inverter. For the radiation loss $\Delta p_{h, l o s s, t}$ of the right side of Eq. (5), the heat storage loss (which is assumed to be $2 \%$ over an entire day) is taken into consideration, and the $C O P_{h p}$ of the heat pump is usually set to 3.5 . Table 2 presents the equipment unit prices and the unit fuel price, and the values within the

Table 2 The unit prices for the setup Japanese yen $(1 \mathrm{USD}=81 \mathrm{JPY})$

\begin{tabular}{|ll|}
\hline SOFC & $640,000 \mathrm{JPY} / \mathrm{kW}$ \\
Photovoltaics & $82,200 \mathrm{JPY} / \mathrm{kW}$ \\
Tidal power & $400,000 \mathrm{JPY} / \mathrm{kW}$ \\
generator & $100,000 \mathrm{JPY} / \mathrm{kW}$ \\
Heat pump & $50,000 \mathrm{JPY} / \mathrm{kWh}$ \\
Battery & $21,000 \mathrm{JPY} / \mathrm{kWh}$ \\
Heat storage tank & $110,000 \mathrm{JPY} / \mathrm{kW}$ \\
Power conditioner & $4.7 \mathrm{JPY} / \mathrm{kWh}$ \\
Natural gas & \\
\hline
\end{tabular}

Natural gas

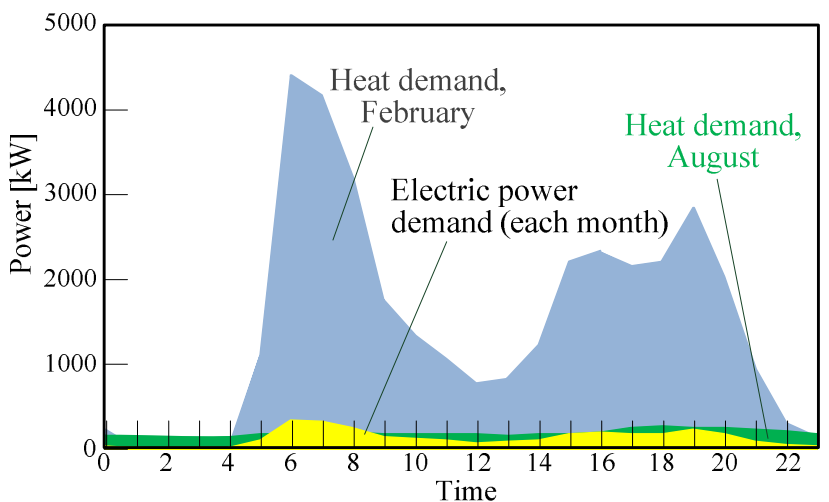

Fig. 8 The electric power and heat demand of Toetoko and Sakaeura 


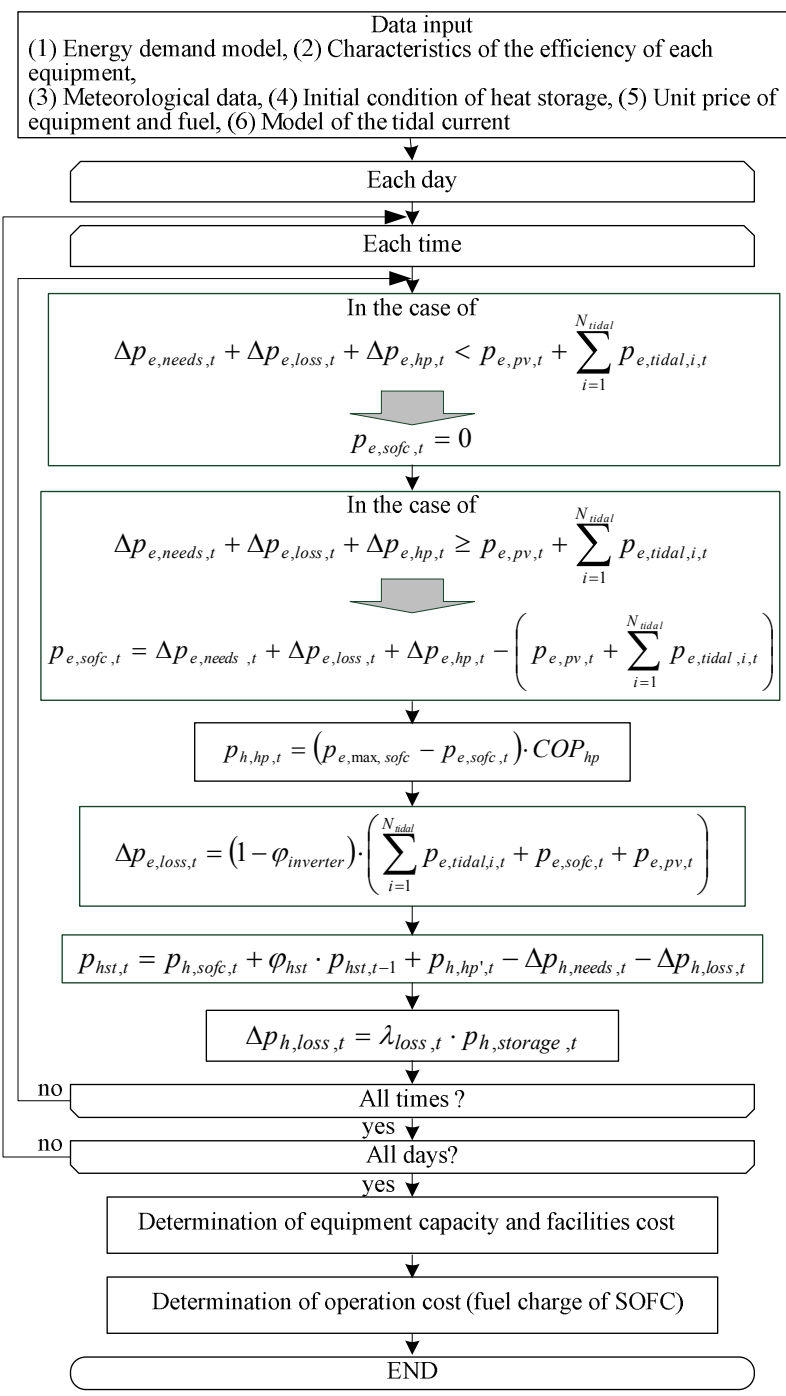

Determination of the production of electricity of SOFC in the case of supplying

(d) the amount of sum totals of power consumption only with green energy. Capacity of equipment is shown in Table 3 .

Determination of the production of electricity of SOFC when the amount of sum

(e) totals of power consumption is larger than green energy.

The losses are described to Section 4.2.

Determination of the heat power of the heat

(f) pump by surplus power. COP of heat pump was set up uniformly 3.5.

(g) Calculation of the power loss by the inverter and the converter The loss is described to Section 4.2.

Determination of the amount of heat storage.

(h) Electric power and heat demand were shown in Fig. 8.

(i) Calculation of heat storage loss.

(j)

(k)

Calculation of the facilities cost by equipment (1) capacity and the unit price (Table 2) of equipment.

(m) Fuel cost for 15 days (operation cost) is calculated using the fuel consumption of the $\mathrm{SOFC}$, and the unit price of natural gas.

Fig. 9 The analysis flow

table determine the product price for 2012 in Japan, for reference.

\subsection{Energy Demand of the Saroma Lake Surrounding Area}

The total quantity demand of electric power and heat for an average residence and the electric power consumption of the harbor facilities are summed to a set value of $60 \mathrm{~kW}$; accordingly, the electricity demand pattern and heat demand pattern of the SLMG are shown in Fig. 8. However, there are 853 residents (227 houses) to whom energy is supplied from the SLMG. Because the electricity demand is based on household appliances, such as electric lights, etc., and the space heating load is included in the heat demand, the differences between the electricity demand patterns for each month are minimal. The minima and maxima of the power load are shown in Fig. 7 as $117 \mathrm{~kW}$ and $240 \mathrm{~kW}$, respectively, and the average value is $164.3 \mathrm{~kW}$. The maximum electric power load appears at 6:00 in the morning in February, each year. The corresponding power consumption and heat load described above for a heat pump of $\mathrm{COP}=3.5$ is $1400 \mathrm{~kW}$.

\subsection{Procedure of Investigation}

\subsubsection{Procedure}

The operation method of the system and the operational costs are investigated for half of February (approximately 15 days) to identify the largest heat-to-power ratio and the maximum energy consumed in the area surrounding Saroma Lake. In the analysis, the capacity of the composition equipment of the system is first determined. Next, according to 
the analysis flow shown in Fig. 9, the operation method, facility costs, and operational costs of the system are obtained. Here, the operational costs of the system are integrated with the amount of fuel (natural gas) consumed by the SOFCs over each sampling period of 15 days. Furthermore, after modifying the capacity of the equipment included in the system, the operational method, the facility costs, and the operational costs are obtained using the procedure described above. The relationships between the operational method and the costs are investigated with respect to the combination of installed capacity over a wide range, such that the combined optimal equipment capacity of the SLMG can be obtained.

\subsubsection{Analysis Flow}

The operational flow analysis of the proposed system is shown in Fig. 9. (a) to (m), with the process for each block expressed on the right side of Fig. 8. The initial values, such as the efficiency of the energy demand (Fig. 8), the efficiencies and losses associated with the equipment (Section 4.2), the amount of insolation (Fig. 3), the initial value of the heat storage tank (equal to 0 ), the unit price of both the equipment and the fuel (Table 2), and the model of the tidal current (Fig. 5 (d)), are all input into (a) in the figure.

The production of electricity by the SOFCs to meet the total power consumption demand is provided by a green energy approach $((\mathrm{d}))$, while the cases in which the total power consumption exceeds the green energy production ((e)) are determined in Figs. 9 (d) and (e). However, because the heat-to-power ratio in winter is large, the SOFCs always operate within the rated state, in which the heat pump ((f)) transfers surplus power into the heat storage tank $((\mathrm{h}))$. Moreover, the power losses associated with the inverters and the converters are calculated in (g), and the heat storage loss is calculated in (i). Furthermore, the facility costs are calculated based on the equipment capacity and the unit price (Table 2) of equipment in (1), and the fuel cost (operational cost) of the SOFCs for 15 days is obtained from the unit price of natural gas in $(\mathrm{m})$.

\section{Analysis Results}

\subsection{Installed Capacity and Cost}

Figure 10 (a) displays the facility costs obtained in the analysis of Section 4 and the results of the operational costs for work-hours over 20 years, as estimated from the fuel consumption for the 15-day period from February 5th to 19th, 2010. Table 3 is the combination of the equipment used for analysis. Although the characteristics of the proposed system are nonlinear, a partial solution does not appear. Although the rated capacity of the SOFCs is set at $550 \mathrm{~kW}$, this rated capacity combines the installed capacity from which the sum total of the facility costs and operational costs serves as the minimum. The minimum capacity at the time of supplying electric power and heat in a representation day in February by one set of SOFC is $550 \mathrm{~kW}$. When the installed capacity of the tidal power generators and the PV increases, the rapid rise in the facility costs can be found from the result of Fig. 10 (a). The system is the cheapest to operate when the PV system is not introduced, but instead, when a set of 10 to 20 tidal power generators are used. Moreover, based on the present energy supply method (i.e., a commercial electric power supply with a kerosene boiler), the time required to recover the minimum cost of the proposed system is approximately ten years. However, the maintenance costs are not included in the analysis cost results because there are a variety of unknown aspects with respect to the maintenance cost of these facilities.

Table 3 Combination of equipment capacity

\begin{tabular}{|l|l|l|l|}
\hline Case A: & Tidal power generator $(5 \mathrm{~kW}) 0 \mathrm{set}$, & Heat Pump $5000 \mathrm{~kW}$, & Heat storage 27000 MJ $(7500 \mathrm{kWh})$ \\
\hline Case B: & Tidal power generator $(5 \mathrm{~kW}) 0$ sets, & Heat Pump $2000 \mathrm{~kW}$, & Heat storage $36000 \mathrm{MJ}(10000 \mathrm{kWh})$ \\
\hline Case C: & Tidal power generator $(5 \mathrm{~kW}) 50 \mathrm{sets}$, & Heat Pump $1500 \mathrm{~kW}$, & Heat storage $32400 \mathrm{MJ}(9000 \mathrm{kWh})$ \\
\hline Case D: & Tidal power generator $(5 \mathrm{~kW}) 100$ sets, & Heat Pump $2000 \mathrm{~kW}$, & Heat storage $36000 \mathrm{MJ}(10000 \mathrm{kWh})$ \\
\hline Case E: & Tidal power generator $(5 \mathrm{~kW}) 100$ sets, & Heat Pump $5000 \mathrm{~kW}$, & Heat storage $54000 \mathrm{MJ}(15000 \mathrm{kWh})$ \\
\hline Case F: & Tidal power generator $(5 \mathrm{~kW}) 1000$ sets, & Heat Pump $5000 \mathrm{~kW}$, & Heat storage $32400 \mathrm{MJ}(7500 \mathrm{kWh})$ \\
\hline
\end{tabular}




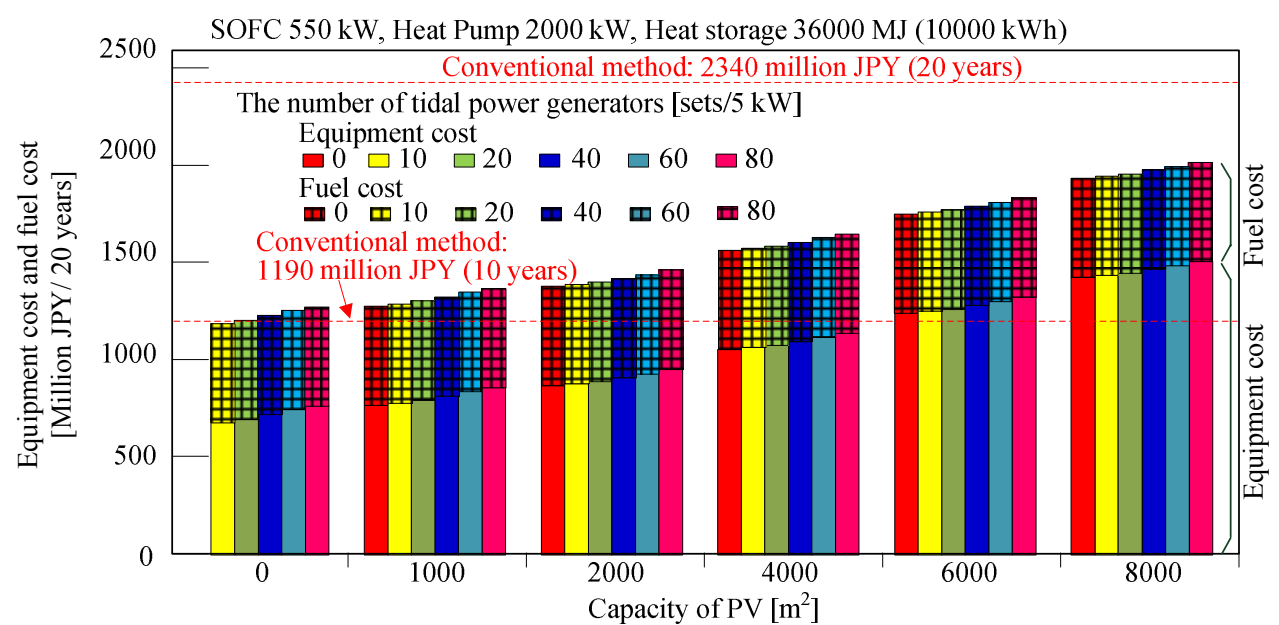

(a) Influence of the installation amounts of the photovoltaic and tidal power generators

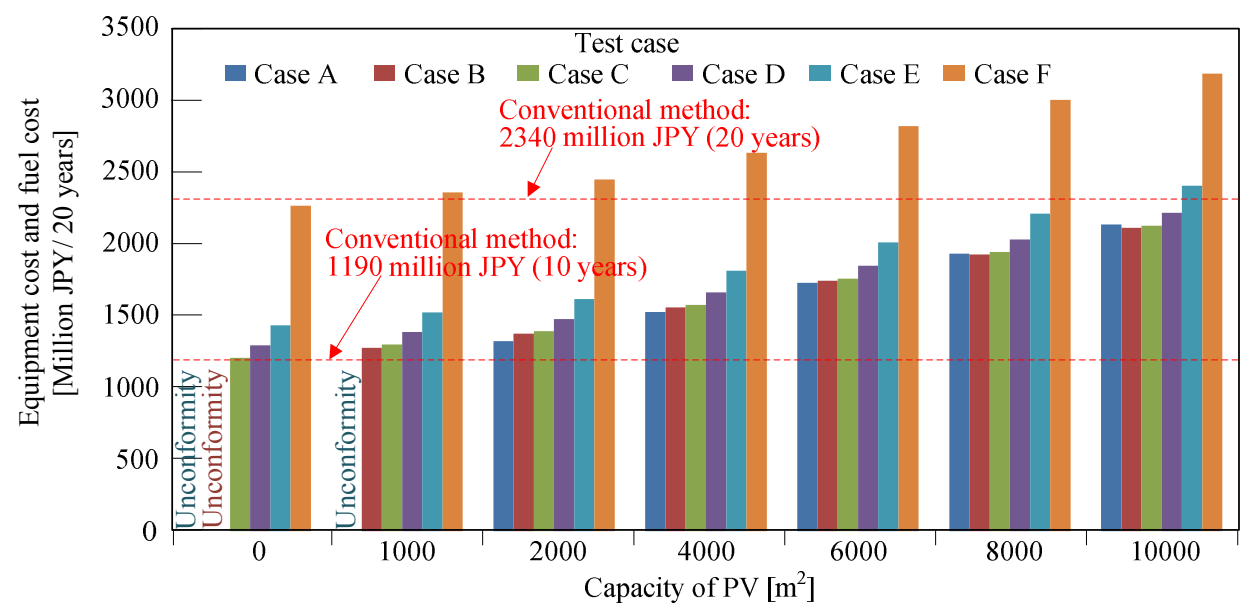

(b) The conditions of the various equipment capacities (SOFC $550 \mathrm{~kW}$ )

Fig. 10 Analysis results of the equipment cost and the fuel cost

However, Fig. 10 (b) shows the total value (for 20 years of operation) of the facility costs and operational costs for the combinations of various capacities of the PV, the tidal power generators, the heat pump, and the heat storage tank. The bottom of the figure presents the composition of the facilities (Case A to Case F). If the number of PV and tidal power generators is increased, the capacity and fuel consumption of the SOFCs decrease, yet the equipment cost increases significantly. Because the maximum production of electricity in tidal power generation is not necessarily obtained at all times, the capacity of the SOFCs and the net reduction in fuel costs are not altered by an increase in the number of tidal power generators introduced. To increase the rate of electricity production from the tidal power generators and the PV, leveling of the electric power supply and the demand is considered to be effectively carried out by the introduction of accumulation-of-electricity equipment, but it is also expected that the presence of additional equipment will significantly increase the cost of the SLMG.

Because the cost of the SLMG is based on the energy demand in February, which has a significant heat demand, the capacity of the heat pump and heat storage tank becomes large, and the plans associated with the heat equipment influence the cost greatly. However, if the capacity of the heat storage tank is small, the allowed quantity of heat from the heat pump and the exhaust heat of the SOFCs is reduced, restricting the surplus power that can be generated. Hence, it is important to use dynamic operation planning to optimize the capacity of the heat storage tank to determine the overall cost of the SLMG. 


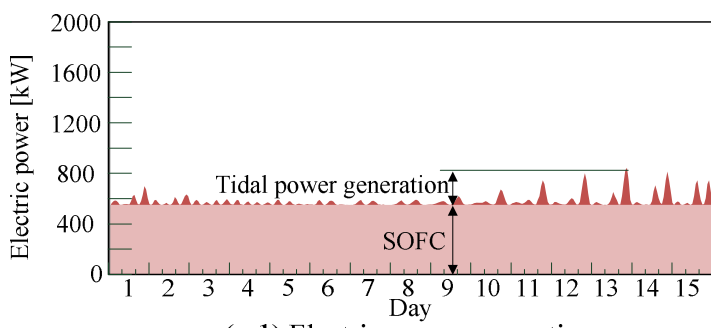

(a-1) Electric power generation

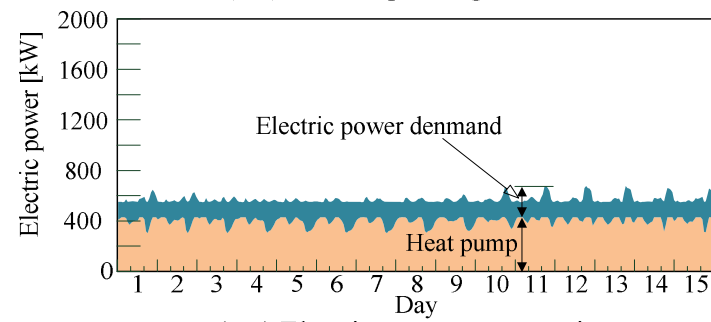

(a-2) Electric power consumption

Case C: PV $0 \mathrm{~m}^{2}$. Tidal power generator $(5 \mathrm{~kW}) 50$ sets, Heat Pump $1500 \mathrm{~kW}$, Heat storage $32400 \mathrm{MJ}$ (9000 kWh)

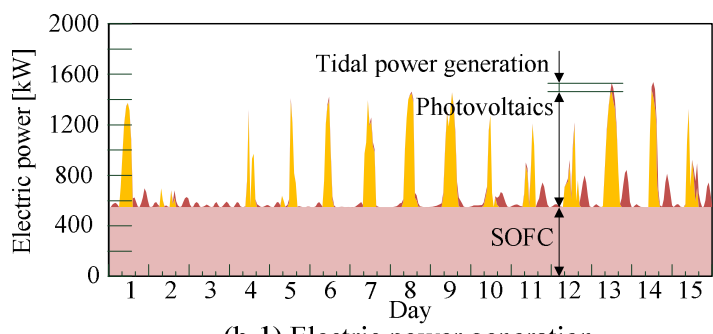

(b-1) Electric power generation

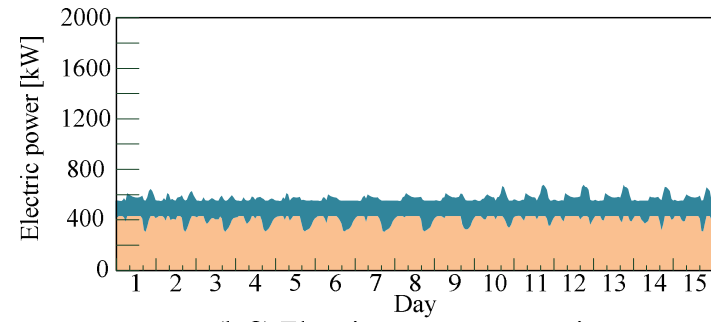

(b-2) Electric power consumption

Case C: PV $10000 \mathrm{~m}^{2}$. Tidal power generator $(5 \mathrm{~kW}) 50$ sets, Heat Pump $1500 \mathrm{~kW}$, Heat storage $32400 \mathrm{MJ}(9000 \mathrm{kWh})$

Fig. 11 Analysis results for the operation of electric power

\subsection{Operation Planning}

Figure 11 shows the results of analysis for the operation plan with respect to electric energy. In Fig. 11, a system configuration based on Case C (shown under Fig. 10 (b)) is used: Fig. 11 (a) does not include a PV system while Fig. 11 (b) has a PV installation of $10,000 \mathrm{~m}^{2}$. Although Figs. 11 (a-1) and (b-1) show the operation results for the electric power supply, Fig. 11 (a-1) does not include the PV output. However, Figs. 11 (a-2) and (b-2) show the operation results for the power consumption, and Figs. 11 (a-2) and (b-2) show the power consumption of the electricity demand and the heat pump. Because a significant quantity of heat is demanded in February, the electric power consumed by the heat pump is mainly supplied from the SOFCs. Therefore, the rate of the electric power supplied by the SOFCs is very large in Figs. 11 (a-1) and (b-1). The difference between the power supply and the power consumption (electricity demand and heat pump) provided by green energy is given by the output control of the SOFCs for seasons in which there is a small heat demand (electric power load following operation). However, because a significant quantity of heat is produced by the heat pump during seasons with a high heat demand, the operating hours of the SOFCs are long (heat load following operation). Moreover, a large-area PV system is introduced in the case of Fig. 11 (b-1), and the scale of the heat pump and the heat storage tank must correspond with the peak production of electricity of the PV. Therefore, one must use planning to reduce the capacity of the heat equipment by attaining a level electric power supply and demand, specifically by introducing accumulation-of-electricity equipment.

\subsection{Electric Power Quality of the SLMG}

\subsubsection{Characteristics of the Electric Power Input to the Demand Side}

The electric power quality of the SLMG is verified using MATLAB/Simulink 2012a. The electric power system for Case C (Figs. 11 (b-1) and (b-2)) is accompanied by a large-area PV system $\left(1000 \mathrm{~m}^{2}\right)$ and is further investigated in this section. The output of the $\mathrm{PV}$ and the tidal power generators are introduced with fluctuations into Case $\mathrm{C}$, and the stable supply of electric power is indefinite. When an electric power system is accurately controlled, the stable time of the transient response to a load change is usually within tens of milliseconds. Hence, in this paper, 1 hour of real time is shortened to $0.1 \mathrm{~ms}$, and the response characteristics of the SLMG while carrying out the step input of the electric power load pattern (Fig. 8) are investigated for each time point for a representative day in February. 


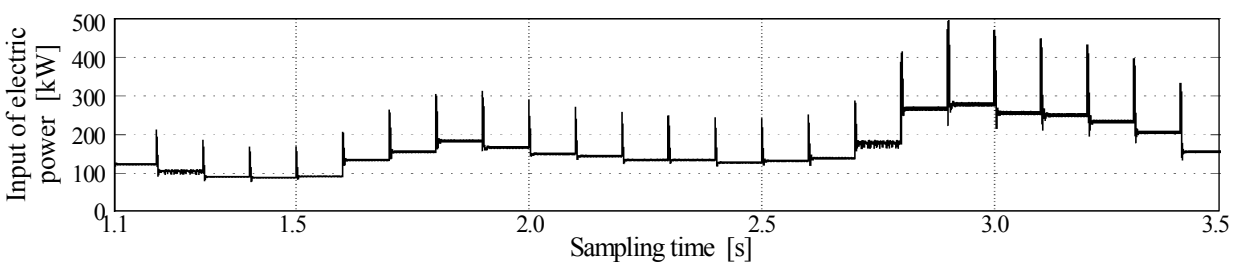

(a) The input to the electric power load

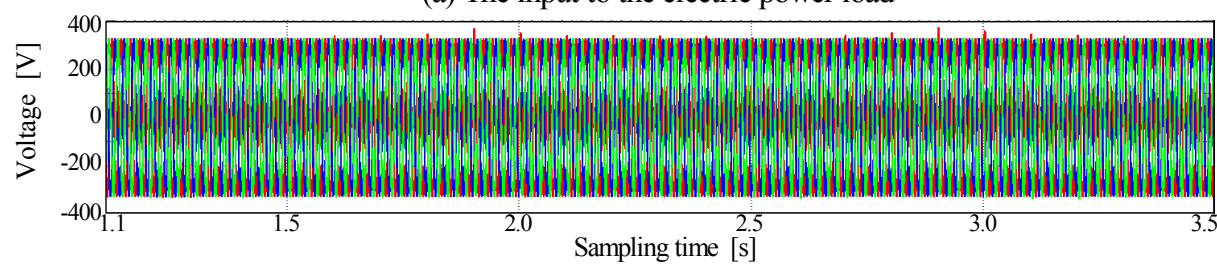

(b) Phase to phase voltage of the electric power load(three-phase AC circuits)

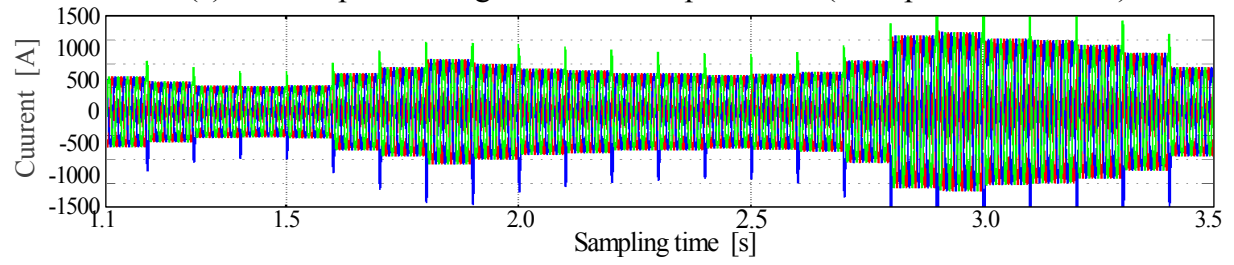

(c) Phase current of the electric power load (three-phase AC circuits )

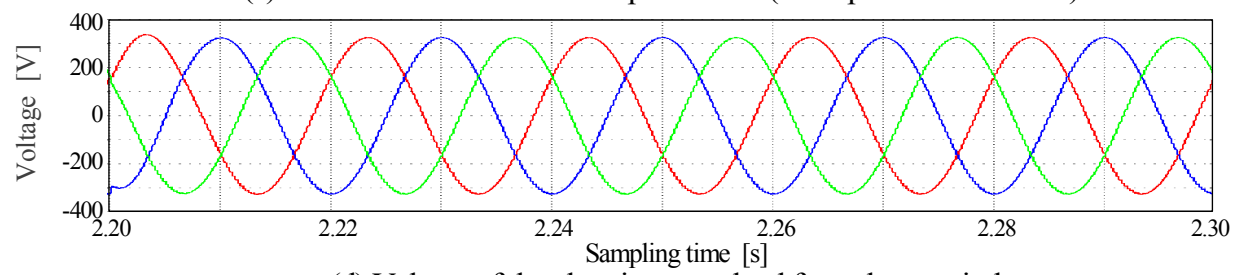

(d) Voltage of the electric power load for a short period

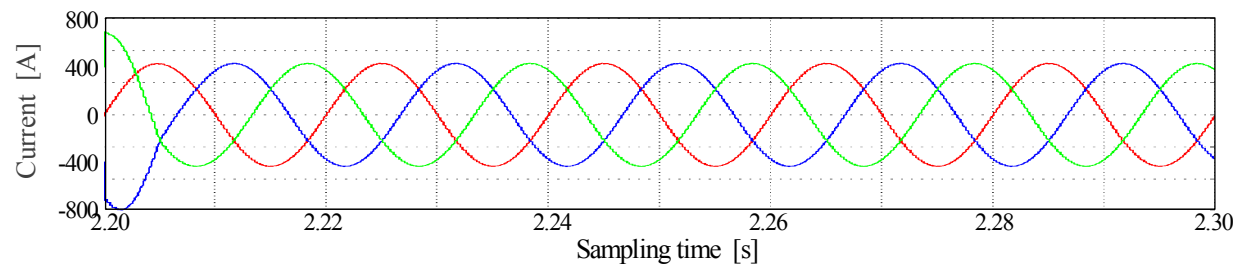

(e) Current of the electric power load for a short period

Fig. 12 The effective power, voltage and current on the bus line of the electric power demand

Figure 12 shows the analysis results of the electric power characteristics supplied to the user load; these results are the empirical results of measuring equipment (1), as given in Fig. 2. The start time of Fig. 12 is $1.1 \mathrm{~s}$; this time was selected to account for the preparation period that follows the cold start of the system, which lasts from $0 \mathrm{~s}$ to $1.1 \mathrm{~s}$. If the rapid load change due to the step input is added to the SLMG, an instantaneous rise in the electric power can be identified as the inrush of current occurs, as shown in Fig. 12 (a). However, because the rapidly rising, large step input is not added to the SLMG by the actual load, it is expected that the inrush current will be suppressed.

Figures 12 (b) and (c) show the results of the phase voltage and phase current analyses of the three-phase alternating current applied to the load. Figures 12 (b) and (c) show that the inrush current is large, although there are few instant voltage rises in the case of the rapid load change. There is almost no fluctuation in the voltage for any time, and the current is appropriately controlled, corresponding to the magnitude of the load. Figures 12 (d) and (e) display the results of the phase voltage and phase current analyses of the three-phase alternating current during the interval from $2.20 \mathrm{~s}$ to $2.30 \mathrm{~s}$ (Figs. 12 (b) and (c) are expanded along the time axis). Although the current wave form at $2.20 \mathrm{~s}$ in Fig. 12 (e) changes according to the inrush current, the other current zones and analysis results of the voltage of Fig. 12 (d) serve as suitable sine waves. As a result, the electric power quality of the proposed SLMG as input into the load by the user is satisfactory. 


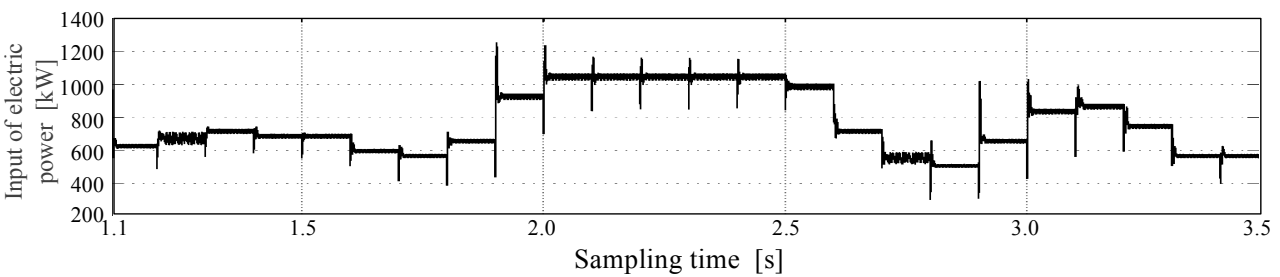

(a) The electric power input to the heat pump

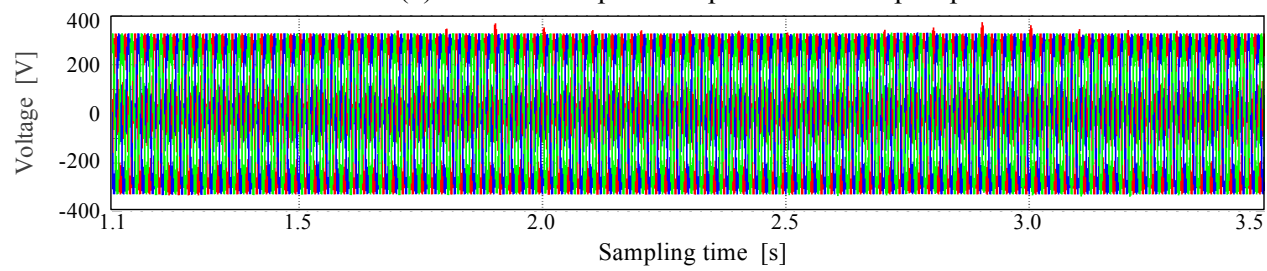

(b) Phase-to-phase voltage of the electric power load of the heat pump (three-phase AC circuits )

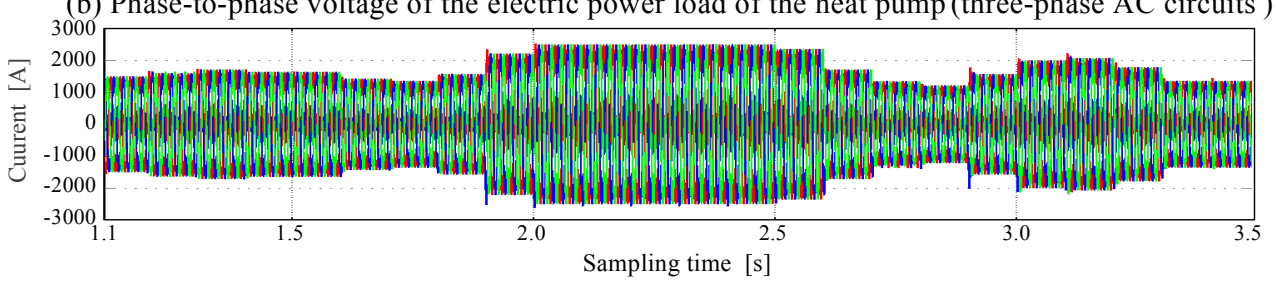

(c) Phase current of the electric power load of the heat pump (three-phase AC circuits )

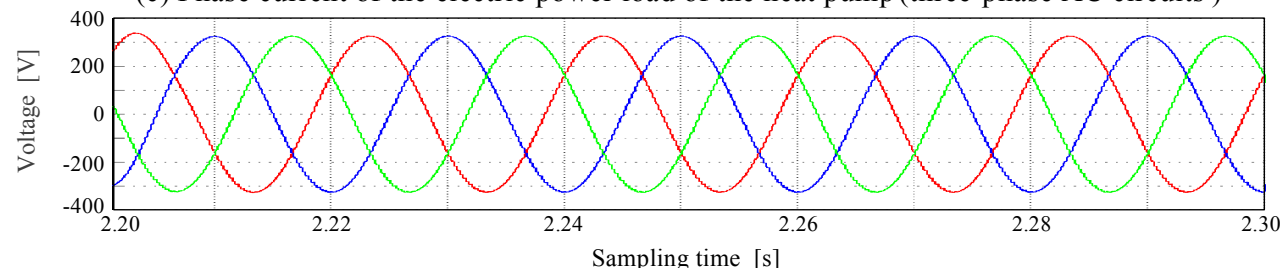

(d) Voltage of the electric power load of the heat pump for a short period

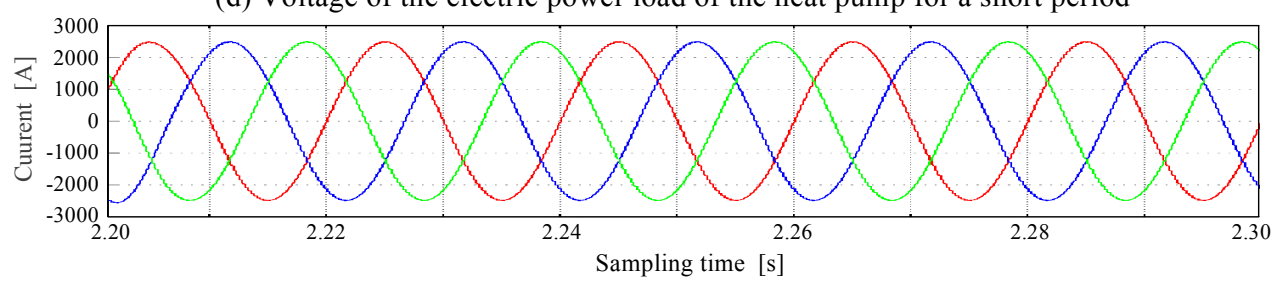

(e) Current of the electric power load of the heat pump for a short period

Fig. 13 The effective power, voltage and current on the bus line of the electric power load of the heat pump

\subsubsection{Characteristics of the Electric Power Input to the Heat Pump}

Figure 13 shows the analysis results of the electric power supplied to the heat pump, as determined by measuring equipment (2) and shown in Fig. 2. Figure 13 (a) shows the electric power supplied to the heat pump, and Figs. 13 (b) and (c) show the phase voltages and phase currents of the three-phase alternating current, respectively. Moreover, enlarged views along the direction of the time axis of Figs. 13 (b) and (c) are shown in Figs. 13 (d) and (e). The voltage and current are good waveforms, although a peak in the electric power can be seen, as a result of the incoming current. Although a heat pump of high capacity $(1500 \mathrm{~kW})$ is installed in Case $\mathrm{C}$, the changes in the power consumption of the heat pump do not significantly influence the electric power quality of the SLMG. Therefore, the electric power quality of the SLMG introduced into the cold district, which is accompanied by a high heat-to-power ratio, is sufficiently maintained.

\section{Conclusions}

The supply characteristics for electric power and heat in the Saroma Lake green microgrid (SLMG) were investigated by the interconnection of tidal power generators 
installed near the lake inlets of Saroma Lake; the microgrid further included the use of PV (photovoltaics) and SOFC (solid oxide type fuel cell) technologies, with numerical approaches used in the analysis. The equipment and operational costs were identified from the analysis results, based on the equipment operation method outlined in this paper using energy balance equations. Further, the electric power quality of the power transmission was analyzed using MATLAB/Simulink, and the following conclusions can be made.

(1) According to the unit price of the assumed energy equipment, the composite system with a $50-\mathrm{kW}$ to $100-\mathrm{kW}$ tidal power generation, a $550-\mathrm{kW}$ SOFC system, a $1500-\mathrm{kW}$ to $2000-\mathrm{kW}$ heat pump and a heat storage tank with a capacity of $32400 \mathrm{MJ}$ to $36000 \mathrm{MJ}$ showed high cost performance. The time required to recover the system costs are described above based on the present energy supply method (commercial electric power supply and a kerosene boiler), with a total of less than ten years. However, because there are many unknown aspects with respect to the maintenance cost of equipment and personnel expenses, such costs are not included in this estimation.

(2) There is a significant heat demand during winter as well as a high heat-to-power ratio. Therefore, the total facility cost of the heat equipment is high. Moreover, the use of heat from the heat pump and the exhaust heat of the SOFC is restricted by the capacity and operational method of the heat storage tank. The dynamic operation planning for the heat pump and the heat storage tank influences the cost of the system greatly as well as the operation planning for the electric power.

(3) Because the electric power produced by the PV system and the tidal power generators is variable, the scale of the heat pump and the heat storage tank must be great when the production capacity of the green energy sources is large.

Therefore, it is necessary to attempt to level the electric power supply with the use of accumulation-of-electricity equipment as well as to consider reductions in the capacity of the heat equipment used.

(4) Synchronization of the frequencies of the power supplies was attempted by issuing control signals from a system controller to the PV and tidal power generator inverters, based on the electric power of the SOFCs. As a result, the frequency, voltage, and waveform of the electric power supplied to the load of the user and the heat pump were good. However, if a step input is given to the load, a peak in the electric power appears as the result of inrush current. However, because the actual load is not accompanied by a rapid change, such as a step input, the peak in electric power based on the incoming current is expected to be controlled. The electric power quality of power transmission by the SLMG was satisfactory, even when accompanied by a large heat-to-power ratio.

\section{Acknowledgments}

This work was partially supported by the TEPCO (Tokyo Electric Power Co., Inc.) Memorial Foundation 2012. We appreciate the support that TEPCO has contributed to this work.

\section{Nomenclatures}

\begin{tabular}{|c|c|c|c|c|c|}
\hline$C_{l m}$ & $:$ & proportionality coefficient & $m$ & $:$ & mass flow rate $[\mathrm{kg}]$ \\
\hline$C O P_{h p}$ & $:$ & coefficient of performance & Greek char & ters & \\
\hline$e$ & $:$ & voltage $[\mathrm{V}]$ & $\rho_{w}$ & $:$ & density of seawater $\left[\mathrm{kg} / \mathrm{m}^{3}\right]$ \\
\hline$m$ & : & mass $[\mathrm{kg}]$ & $\eta$ & $:$ & efficiency \\
\hline$N$ & : & number & Subscript & & \\
\hline PV & : & photovoltaic & facilities & $:$ & port facilities \\
\hline$P_{w}$ & : & kinetic power $[\mathrm{N}]$ & fuel & $:$ & fuel \\
\hline$p_{e}$ & : & electric power $[\mathrm{kW}]$ & hst & $:$ & heat storage tank \\
\hline$p_{h}$ & : & heat $[\mathrm{kW}]$ & $h p$ & $:$ & heat pump \\
\hline$\Delta p_{e}$ & $:$ & consumption of electric power & loss & $:$ & loss \\
\hline
\end{tabular}


$\Delta \bar{p}_{e, S} \quad: \quad$ mean consumption of electric power in Sakaeura [kW] power in Toetoko $[\mathrm{kW}]$

$\Delta p_{h} \quad: \quad$ consumption of heat $\quad[\mathrm{kW}]$

SOFC : solid oxide fuel cell

$t \quad$ : sampling time [hour]

$v \quad:$ flow velocity $[\mathrm{m} / \mathrm{s}]$
$\Delta \bar{p}_{e, T} \quad:$ mean consumption of electric

$S \quad$ : cross section of flow pass

$\begin{array}{lll}\text { needs } & : & \text { demands } \\ p v & : & \text { photovoltaic } \\ S & : & \text { Sakaeura } \\ \text { sofc } & : & \text { SOFC } \\ T & : & \text { Toetoko } \\ \text { tidal } & : & \text { tidal }\end{array}$

References

[1] Kyozuka Y. An experimental study on the Darrieus-Savonius turbine for the tidal current power generation. JSME Journal of Fluid Science and Technology, 2008, 3(3), 439-449.

[2] Deog H D, Suzuki K. Power generation characteristics of a novel horizontal tidal current power generation system installed in the Akashi Strait of Japan. Sustainable Energy Technologies (ICSET), 2010 IEEE International Conference, 2010, 1-6.

[3] Dolman S, Simmonds M, Towards best environmental practice for cetacean conservation in developing Scotland's marine renewable energy, 2010, 34(5), 1021-1027.

[4] Johnson K, Kerr S, Side J, Accommodating wave and tidal energy - Control and decision in Scotland, Ocean \& Coastal Management, 2012, 65, 26-33.

[5] Bae Y H, Kim K O, Choi B H, Lake Sihwa tidal power plant project, Ocean Engineering, 2010, 37(5-6), 454-463.

[6] Lee D S, Oh S H, Yi J Y, Park W, Cho H S, Kim D G, Eom H M, Ahn S J, Experimental investigation on the relationship between sluice caisson shape of tidal power plant and the water discharge capability, Renewable Energy, 2010, 35(10), 2243-2256.

Homepage of Japan Metrological

Agency. http://www.data.jma.go.jp/obd/stats/etrn/index.php, 2012.

[8] Abashiri development and construction department, Hokkaido regional development bureau report on investigation of flow regime of Lake Saroma fishing port, and other work 2010. in Japanese.

[9] Staffell I, Green R, The cost of domestic fuel cell micro-CHP systems, International Journal of Hydrogen Energy, Available online 27 November 2012.

[10] Japan hydrographic association, Surveillance study for wreck-at-sea prevention in ocean space with complicated flow regime Part 2, 2009. in Japanese.

[11] Japan Oceanographic Data Center, Hydrographic and Oceanographic Department, Japan Coast Guard, http://www1.kaiho.mlit.go.jp/jhd-E.html, 2012. 